\title{
Novel visual system homeobox 1 gene mutations in Turkish patients with keratoconus
}

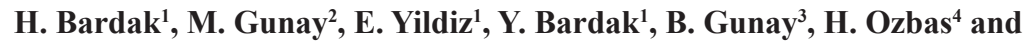 \\ O. Bagci $^{4}$
}

${ }^{1}$ Department of Ophthalmology, Haydarpaşa Numune Training and Research Hospital, Uskudar, Istanbul, Turkey ${ }^{2}$ Department of Ophthalmology,

Zeynep Kamil Maternity and Children's Diseases Training and Research Hospital, Uskudar, Istanbul, Turkey

${ }^{3}$ Department of Ophthalmology, Umraniye Training and Research Hospital, Umraniye, Istanbul, Turkey

${ }^{4}$ Department of Medical Genetics, Faculty of Medicine, Süleyman Demirel University, Isparta, Turkey

Corresponding author: H. Bardak

E-mail: handanbardak@yahoo.com.tr

Genet. Mol. Res. 15 (4): gmr15049024

Received July 25, 2016

Accepted September 12, 2016

Published November 3, 2016

DOI http://dx.doi.org/10.4238/gmr15049024

Copyright $(\underset{2}{ } 2016$ The Authors. This is an open-access article distributed under the terms of the Creative Commons Attribution ShareAlike (CC BY-SA) 4.0 License.

\begin{abstract}
The aim of this study was to screen the visual system homeobox 1 (VSX1) gene in Turkish patients with keratoconus (KC). The patient group consisted of 44 patients who had undergone corneal transplant surgery before the age of 30 , for advanced and rapidly progressive $\mathrm{KC}$. The control group comprised 250 healthy individuals. We detected two missense mutations, D144N and D295Y, in exon 2 and exon 5 of the $V S X 1$ gene, respectively, using next-generation sequencing analysis. The pathologic effects of the D144N and D295Y missense mutations on protein function were determined with bioinformatic
\end{abstract}


analysis tools, SIFT, PolyPhen, and MutationTaster. Aspartic acid at the 144th position was more preserved among species than aspartic acid at the 295th position of the VSX1 protein. In the control group, five different genetic variations were detected, two of which (rs8123716 and rs12480307) were synonymous with variations in the patient group. Our results suggested that the D144N and D295Y mutations might have a role in the pathogenesis of $\mathrm{KC}$ disease.

Key words: Keratoconus; Mutation; Next-generation sequencing; VSX1

\section{INTRODUCTION}

Keratoconus $(\mathrm{KC})$ is a progressive degeneration, thinning, and anterior protrusion of the cornea that results in myopia and irregular astigmatism, leading to low vision (Moreira et al., 2013). The prevalence of KC varies among different ethnic groups. Studies suggest that the prevalence and incidence rates of $\mathrm{KC}$ are much higher in Asian populations than in Caucasian populations (Georgiou et al., 2004). The estimated incidence of KC varies between 1 in 500 and 1 in 2000 individuals in any general population, and the estimated prevalence is 54.5 per 100,000 individuals (Rabinowitz, 1998).

As $\mathrm{KC}$ mainly affects working-age adults, the magnitude of its impact on public health is more severe than would be expected, given its prevalence and clinical severity. $\mathrm{KC}$ is associated with a significantly impaired vision-related quality of life that continues to decline over time. It is one of the major indications for corneal transplant (Kymes et al., 2008).

The disease usually appears during puberty or the early 20 s and stabilizes by the fourth decade of life (Rabinowitz, 1998; Ertan and Muftuoglu, 2008). Although KC affects both genders, it develops earlier and progresses more rapidly in men than in women. It is usually a bilateral disease (Georgiou et al., 2004).

Clinical signs of $\mathrm{KC}$ are well known. The V-shaped indentation observed in the lower eyelid during downward gaze (Munson's sign), the sharply focused light beam near the nasal limbus produced by lateral corneal illumination (Rizzuti's sign), a scissoring reflex, and an oildroplet reflex (Charleaux sign) are all highly suggestive of KC (Rabinowitz, 1998). Corneal clouding, corneal edema, and acute hydrops caused by sudden breaks in Descemet's membrane can also be observed in KC patients. Additionally, Fleischer's ring can be seen around the base of the corneal cone, formed by hemosiderin accumulation. Moreover, prominent corneal nerves, corneal ectasia accompanied by thinning, subepithelial and anterior stromal scars in Bowman's membrane, and fine parallel lines in the posterior stroma (Vogt's striae) are visible in slit-lamp examination of KC patients (Rabinowitz, 1998). Corneal topography provides early and accurate clinical diagnosis of KC (Gomes et al., 2015).

The pathologic findings in $\mathrm{KC}$ are epithelial thinning, thickening of basement membrane, defects in Bowman's layer, stromal scarring, apoptosis, decreased subbasal nerve density, loss of stromal collagen, and decreased keratocyte density (Gomes et al., 2015).

The exact cause and pathogenesis of $\mathrm{KC}$ are incompletely understood (Wheeler et al., 2012). The complex interaction between genetic and environmental factors contributes to the clinical manifestation of KC. Frequent eye rubbing, use of contact lenses, and exposure to ultraviolet light are mentioned among the environmental factors relevant to

Genetics and Molecular Research 15 (4): gmr15049024 
$\mathrm{KC}$, and although most diagnosed cases are sporadic, $\mathrm{KC}$ can be heritable (Arnal et al., 2011). High concordance in monozygotic twins and a significantly higher prevalence of $\mathrm{KC}$ in first-degree relatives of $\mathrm{KC}$ patients, than in the general population, both indicate a genetic basis for the disease (Wang et al., 2000). Around 6-23\% of the KC patients exhibit a family history with an autosomal dominant or recessive pattern of inheritance (Moreira et al., 2013). KC may also coexist with several rare genetic disorders, including atopy, vernal keratoconjunctivitis, retinitis pigmentosa, Leber congenital amaurosis, mitral valve prolapse, Down syndrome, and noninflammatory connective tissue disorders, such as Ehlers-Danlos syndrome, osteogenesis imperfecta, and joint hypermobility (Rabinowitz, 1998; McGhee, 2009).

Through traditional linkage analysis and candidate gene screening, researchers have identified several loci on different chromosomes linked to KC. However, none of these loci was definitely confirmed as $\mathrm{KC}$-associated genetic factor. There is still a need for replication of these results in other KC families and patients (Davidson et al., 2014). Genome-wide association studies (GWAS) are a powerful tool to investigate the genetic factors of complex traits and diseases like KC ( $\mathrm{Li}$ et al., 2012; Cuellar-Partida et al., 2015). Previous GWAS conducted on both European and Asian populations have identified 11 central corneal thickness (CCT)-associated loci, including common single nucleotide polymorphisms (SNPs) $100 \mathrm{~kb}$ upstream of zinc-finger protein 469 (ZNF469) gene, which is most strongly associated with CCT (Cornes et al., 2012). Homozygous mutations in ZNF469 are also known to cause brittle cornea syndrome type 1, a rare connective tissue disorder characterized by extreme thinning and fragility of the cornea such that it may rupture even in the presence of minor trauma, leading to blindness (Christensen et al., 2010). The association of ZNF469 with CCT in GWAS suggests that this gene may be involved in the synthesis or organization of corneal collagen fibers.

One of the main candidate genes for $\mathrm{KC}$ is the visual system homeobox 1 (VSX1) gene. The protein product of this gene plays a role in craniofacial and ocular development. VSX1 is a paired-like homeodomain transcription factor gene localized to chromosome 20p11.21. Its expression has been observed in the corneal and retinal cDNA libraries (Semina et al., 2000), the inner nuclear layer of the human retina, and the embryonic craniofacial tissue (Hayashi et al., 2000). The human VSX1 gene has five exons that encode for a 365-amino-acid protein with a homeobox DNA-binding domain and a Chx10/Vsx-1 and ceh-10 domain, which is highly conserved among vertebrates (Shetty et al., 2015).

Several mutations of the VSX1 gene (e.g., R166W, L159M, D144R, and H244R) have been identified in patients with KC phenotype (Héon et al., 2002; Mok et al., 2008; Paliwal et al., 2011). However, it is not confirmed that these mutations cause KC (Liskova et al., 2007; Paliwal et al., 2011). Hence, the genetic basis of KC is still unclear (Paliwal et al., 2011; Jeoung et al., 2012; Vincent et al., 2013).

Our study results might provide new genetic markers for $\mathrm{KC}$. With confirmed genetic markers, genetic testing for $\mathrm{KC}$ may lead to early diagnosis, help with risk assessment and levels of prevention involving environmental factors, and even lead to a more effective treatment of $\mathrm{KC}$.

The aim of this study was to screen the VSXI gene using next-generation sequencing (NGS) in Turkish patients who had undergone corneal transplant surgery before the age of 30 for advanced and rapidly progressive $\mathrm{KC}$. To the best of our knowledge, this is the first study screening the VSX1 gene in Turkish population.

Genetics and Molecular Research 15 (4): gmr15049024 


\section{MATERIAL AND METHODS}

\section{Patient recruitment}

The study was approved by the Local Ethics Committee of the School of Medicine, Süleyman Demirel University. Written informed consents were obtained from each participant. The patient database of the Department of Ophthalmology, Haydarpaşa Numune Training and Research Hospital, was searched to identify KC patients who had undergone corneal transplant surgery. The inclusion criterion was a rapidly progressive $\mathrm{KC}$ requiring corneal transplant surgery by the age of 30. Eligible patients were invited to participate in the study.

$\mathrm{KC}$ diagnosis was based on a patient history of decreased vision in one or both eyes caused by progressive irregular astigmatism, corneal thinning, and protrusion detected by slitlamp examination. Abnormal corneal steepening was confirmed using a Scheimpflug camera combined with Placido discs (Sirius, CSO, Italy).

\section{DNA collection}

The study group included 44 advanced KC patients from Turkey. The control group consisted of 250 unrelated healthy Turkish subjects, with exome sequencing data. All peripheral blood samples were collected at the Department of Ophthalmology, Haydarpaşa Numune Training and Research Hospital, where patients were diagnosed with KC based on clinical investigations. Genomic DNA was isolated from peripheral blood using Realpure Spin Kit (REAL, Durviz, Spain), following manufacturer protocols. Using NGS, all coding exons of the $V S X 1$ gene and their flanking splice site junctions were analyzed.

\section{Targeted NGS}

VSX1 gene sequencing analysis was performed using the MiSeq NGS platform (Illumina Inc., San Diego, CA, USA). Concentration and purity of DNA samples were quantified using ND-1000 spectrophotometer (NanoDrop, Wilmington, DE, USA), and the DNA samples were used at $50 \mathrm{ng} / \mu \mathrm{L}$ concentration for analyses. Exons $1-5$ of the VSX1 gene and their flanking splice site junctions were amplified using PCR primers designed with Primer Designer v.2.0 (Scientific \& Educational Software). PCR products were validated using agarose gel electrophoresis. Additionally, PCR products for each individual were mixed to create PCR pools, which were then purified and quantified. Purifications were done using a NucleoFast ${ }^{\circledR} 96$ PCR kit (Macherey-Nagel GmbH \& Co. Düren, Germany), and purified PCR products were quantified using ND-1000 spectrophotometer. Quantified PCR pools were standardized to $0.2 \mathrm{ng} / \mu \mathrm{L}$. The libraries were prepared with the Nextera XT DNA sample preparation kit (Illumina Inc.), following the manufacturer instructions.

\section{RESULTS}

\section{Patients}

There were 20 female (46.7\%) and 24 male (53.3\%) patients in the KC patient group. The average age of the patient group was $25.30 \pm 2.74$ years (range, 23-32 years). Age and gender distribution of the control group were similar to that of the patient group $(\mathrm{P}>0.05)$.

Genetics and Molecular Research 15 (4): gmr15049024 


\section{DNA sequence analysis of $V S X 1$ by NGS}

In the patient group, four genetic variations in the coding exons of the VSX1 gene and their flanking splice site junctions were detected using NGS. Two of the four genetic variations (rs8123716 and rs12480307) were recorded variations (http://www.ncbi.nlm.nih.gov/projects/ SNP/, accessed on March 1, 2016; http://www.hgvs.org/mutnomen/, accessed on March 1, 2016). The other two previously undescribed variations were missense mutations in exon 2 (D144N) and exon 5 (D295Y). In the control group, five different genetic variations were detected, two of which (rs8123716 and rs12480307) were synonymous with the variations in the patient group (Table 1).

\begin{tabular}{|c|c|c|c|c|c|c|c|}
\hline \multirow[t]{2}{*}{ Group } & \multirow[t]{2}{*}{ Genetic variation } & \multirow[t]{2}{*}{ Protein mutation } & \multirow[t]{2}{*}{ db SNP ID } & \multirow{2}{*}{$\begin{array}{c}\text { MAF/1000 } \\
\text { Genome Project }\end{array}$} & \multirow{2}{*}{$\begin{array}{c}\text { Allele } \\
\text { frequency }\end{array}$} & \multicolumn{2}{|c|}{ Number of cases/control } \\
\hline & & & & & & Homozygous & Heterozygous \\
\hline \multirow[t]{2}{*}{ Case } & c. $18 \mathrm{G}>\mathrm{T}$ & S6 $=$ & rs8123716 & 0.0272 & 0.0136 & - & 1 \\
\hline & \begin{tabular}{|l|l} 
c. $546 \mathrm{~A}>\mathrm{G}$ \\
\end{tabular} & $\mathrm{A} 182=$ & \begin{tabular}{|l|} 
rs 12480307 \\
\end{tabular} & 0.2903 & 0.0454 & 1 & 2 \\
\hline \multirow{5}{*}{ Control } & c. $546 \mathrm{~A}>\mathrm{G}$ & $\mathrm{A} 182=$ & rs 12480307 & 0.2903 & 0.248 & 23 & 78 \\
\hline & c. $18 \mathrm{G}>\mathrm{T}$ & S6 $=$ & rs8123716 & 0.0272 & 0.004 & - & 2 \\
\hline & \begin{tabular}{|l} 
c. $432 \mathrm{C}>\mathrm{G}$ \\
\end{tabular} & D144E & $\begin{aligned} \mathrm{rs} 140122268 \\
\end{aligned}$ & 0.0022 & 0.004 & - & 2 \\
\hline & c. $627+84 \mathrm{~T}>\mathrm{A}$ & \begin{tabular}{|l|} 
Intron variant \\
\end{tabular} & rs56157240 & 0.2905 & 0.242 & 23 & 75 \\
\hline & \begin{tabular}{|l|} 
c. $627+23 \mathrm{G}>\mathrm{A}$ \\
\end{tabular} & Intron variant & rs6138482 & 0.2157 & 0.214 & 15 & 77 \\
\hline
\end{tabular}

\section{Predicting possible impacts of non-synonymous variants}

SIFT, PolyPhen, and MutationTaster bioinformatic analysis tools were used to predict the effects of the two non-synonymous variations, detected in the patient group, on protein function (Adzhubei et al., 2010; Schwarz et al., 2014).

The pathologic effect of the D144N missense mutation on protein function was predicted by all three tools. The D295Y missense mutation was predicted to affect protein function by SIFT and PolyPhen analyses, but was predicted as a polymorphism by MutationTaster (Table 2). In addition, aspartic acid at the 144th position was more preserved than the aspartic acid at the 295th position of the VSX1 protein, among species (Figure 1).

Table 2. Novel mutations detected in the patient group and results of the bioinformatic analysis.

\begin{tabular}{l|c|c|l|l|l}
\hline Patient No. & Genetic variation & Protein mutation & SIFT & MutationTaster & PolyPhen \\
\hline Case 16 & c. $430 \mathrm{G}>\mathrm{A}$ & D144N & $0.08 /$ intolerant & Disease causing & $0.964 /$ probably damaging \\
\hline Case 43 & c. $883 \mathrm{G}>\mathrm{T}$ & D295Y & 0/intolerant & Polymorphism & $0.986 /$ probably damaging \\
\hline
\end{tabular}

\section{DISCUSSION}

Studies have shown that genetic and environmental factors may be involved in the pathogenesis of KC, but its exact etiology and pathophysiology are unknown (Tanwar et al., 2010).

Atilano et al. (2005) reported high level of mitochondrial DNA deletions leading to increased oxidative stress in the corneal tissue of KC patients. Lema and Durán (2005) showed higher levels of inflammatory molecules, matrix metalloproteinase 9, interleukin 6 , and tumor necrosis factor- $\alpha$ in the tear film of KC patients than in the control group, indicating that

Genetics and Molecular Research 15 (4): gmr15049024 
a)

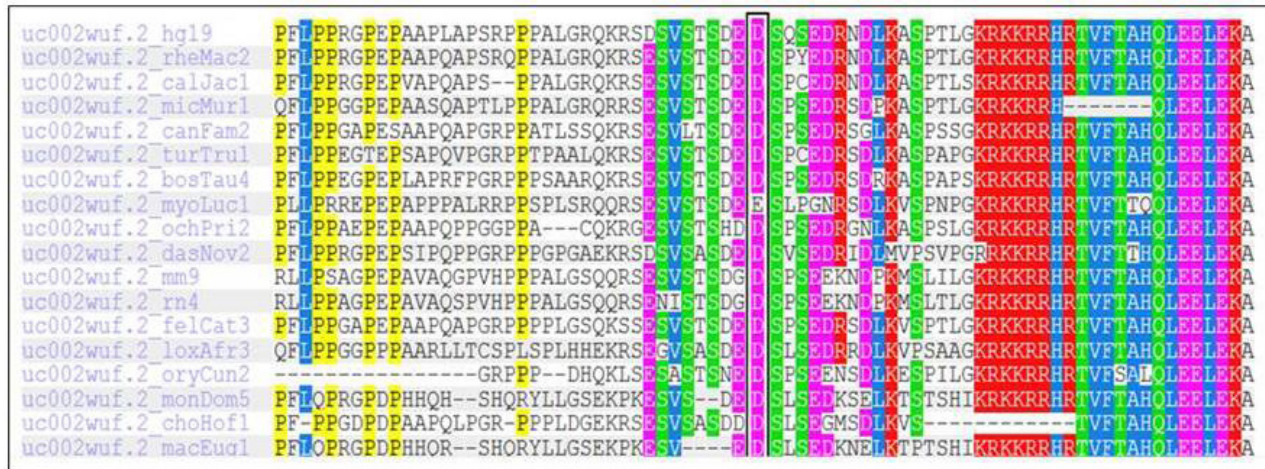

b)

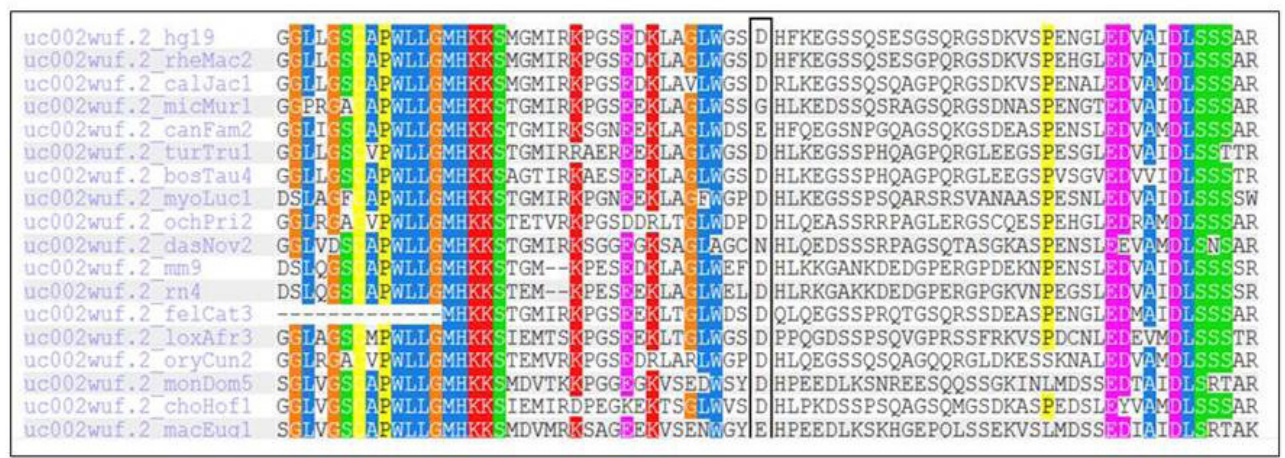

Figure 1. In VSX1 protein, the aspartic acid at the 144th position (a) was more preserved than the aspartic acid at the 295th position (b).

chronic inflammation might be related to pathogenesis of KC. Matthews et al. (2007) found more apoptotic cells in the corneas of $\mathrm{KC}$ patients than in those of unaffected individuals, which may be related to matrix metalloproteinase inhibition by tissue inhibitor of matrix metalloproteinase (TIMP) 1 and TIMP3. De Bonis et al. (2011) found no mutational variants of TIMP3 in 302 unrelated Italian KC patients.

In this study, we analyzed the VSX1 gene in 44 unrelated KC patients and 250 healthy controls with exome sequencing data. VSX1 mutations were first reported in 2002 in patients with posterior polymorphous corneal dystrophy and $\mathrm{KC}$, and initially, two mutations, R166W and L159M, were identified in KC patients (Héon et al., 2002).

VSX1 encodes a paired-like homeodomain protein, which binds to the core of the locus control region of the red and green visual pigment gene cluster and may regulate the expression of the cone opsin genes during embryonic development (Ohtoshi et al., 2004; Watson and Chow, 2011). It is expressed in several ocular tissues, including the retina (Hayashi et al., 2000; Semina et al., 2000; Héon et al., 2002).

$\mathrm{Lv}$ et al. (2015) recently cloned the muscle segment homeobox C (MsxC) gene of the fish Hemibarbus labeo. Sequence analysis of MsxC revealed motif characteristic of the homeobox domain family, whereas whole-mount in situ hybridization showed that $M s x C$ is expressed primarily in the myosepta and brain. In vertebrates, $M s x C$ participates in the regulation of mesenchymal cell differentiation during bone formation. Lv et al. (2015)

Genetics and Molecular Research 15 (4): gmr15049024 
therefore concluded that $M s x C$ might have a role in epithelium-mesenchyme interactions during intermuscular bone formation in H. labeo.

Previous studies in humans and mice did not confirm the expression of VSX1 in the cornea (Héon et al., 2002; Watson and Chow, 2011). Moreover, mouse models with a loss of VSX1 function did not show cornea-related phenotypes (Ohtoshi et al., 2004). Since the original report by Héon et al. (2002), other researchers have examined VSX1 mutations in KC patients (Gajecka et al., 2009; Abu-Amero et al., 2011; Saee-Rad et al., 2011). Most of the identified variants are polymorphic (Wheeler et al., 2012), and it remains unclear whether VSX1 mutations contribute to the pathogenesis of KC (Romero-Jiménez et al., 2010). It is possible that VSX1 mutations affect only a very small percentage of $\mathrm{KC}$ patients, which is consistent with the concept of genetic heterogeneity of $\mathrm{KC}$.

Whole-genome/exome sequencing is useful in the identification of causal mutations in multiplex families with KC (Bamshad et al., 2011; Bick and Dimmock, 2011). Previously identified linkage regions can be helpful in understanding exome or genome sequencing data. The genetic heterogeneity of $\mathrm{KC}$ requires the identification and replication of novel genetic mutations; therefore, our results might help clarify the genetic basis of KC. The VSX1 variants reported in various studies include p.L17P, p.D144E, p.N151S, p.L159M, p.G160V, p.G160D, p.R166W, p.Q175H, p.H244R, and p.P247R (Hayashi et al., 2000; Héon et al., 2002; Mok et al., 2008; Paliwal et al., 2011).

We analyzed coding exons 1-5 of the VSX1 gene and their flanking splice site junctions and found two new mutations in two patients (case 16 and case 43). Both cases appeared to be sporadic, as we found no other instances of $\mathrm{KC}$ among their family members.

To prevent false positive and false negative results of bioinformatic analysis, we used three different bioinformatics tools, SIFT, MutationTaster, and PolyPhen.

With the increased utilization of high-density SNP arrays and whole-genome/exome sequencing technologies, it will become possible to apply genome-wide approaches to identify causal genetic variants in both familial and sporadic forms of $\mathrm{KC}$ at a more rapid pace. Until then, the molecular pathogenesis of $\mathrm{KC}$ remains heterogeneous.

In this study, two novel mutations of VSX1, D144N and D295Y, were found in two unrelated KC patients. It was shown that the aspartic acid at the 144th position was more preserved than the aspartic acid at the 295th position of the VSX1 protein, among species. It was also found that the D144N and D295Y mutations might play a role in the etiopathogenesis of $\mathrm{KC}$ disease.

\section{Conflicts of interest}

The authors declare no conflict of interest.

\section{REFERENCES}

Abu-Amero KK, Kalantan H and Al-Muammar AM (2011). Analysis of the VSX1 gene in keratoconus patients from Saudi Arabia. Mol. Vis. 17: 667-672.

Adzhubei IA, Schmidt S, Peshkin L, Ramensky VE, et al. (2010). A method and server for predicting damaging missense mutations. Nat. Methods 7: 248-249. http://dx.doi.org/10.1038/nmeth0410-248

Arnal E, Peris-Martínez C, Menezo JL, Johnsen-Soriano S, et al. (2011). Oxidative stress in keratoconus? Invest. Ophthalmol. Vis. Sci. 52: 8592-8597. http://dx.doi.org/10.1167/iovs.11-7732

Atilano SR, Coskun P, Chwa M, Jordan N, et al. (2005). Accumulation of mitochondrial DNA damage in keratoconus

Genetics and Molecular Research 15 (4): gmr15049024 
corneas. Invest. Ophthalmol. Vis. Sci. 46: 1256-1263. http://dx.doi.org/10.1167/iovs.04-1395

Bamshad MJ, Ng SB, Bigham AW, Tabor HK, et al. (2011). Exome sequencing as a tool for Mendelian disease gene discovery. Nat. Rev. Genet. 12: 745-755. http://dx.doi.org/10.1038/nrg3031

Bick D and Dimmock D (2011). Whole exome and whole genome sequencing. Curr. Opin. Pediatr. 23: 594-600. http:// dx.doi.org/10.1097/MOP.0b013e32834b20ec

Christensen AE, Knappskog PM, Midtbø M, Gjesdal CG, et al. (2010). Brittle cornea syndrome associated with a missense mutation in the zinc-finger 469 gene. Invest. Ophthalmol. Vis. Sci. 51: 47-52. http://dx.doi.org/10.1167/iovs.09-4251

Cornes BK, Khor CC, Nongpiur ME, Xu L, et al. (2012). Identification of four novel variants that influence central corneal thickness in multi-ethnic Asian populations. Hum. Mol. Genet. 21: 437-445. http://dx.doi.org/10.1093/hmg/ddr463

Cuellar-Partida G, Springelkamp H, Lucas SE, Yazar S, et al. (2015). WNT10A exonic variant increases the risk of keratoconus by decreasing corneal thickness. Hum. Mol. Genet. 24: 5060-5068. http://dx.doi.org/10.1093/hmg/ ddv211

Davidson AE, Hayes S, Hardcastle AJ and Tuft SJ (2014). The pathogenesis of keratoconus. Eye (Lond.) 28: 189-195. http://dx.doi.org/10.1038/eye.2013.278

De Bonis P, Laborante A, Pizzicoli C, Stallone R, et al. (2011). Mutational screening of VSX1, SPARC, SOD1, LOX, and TIMP3 in keratoconus. Mol. Vis. 17: 2482-2494.

Ertan A and Muftuoglu O (2008). Keratoconus clinical findings according to different age and gender groups. Cornea 27: 1109-1113. http://dx.doi.org/10.1097/ICO.0b013e31817f815a

Gajecka M, Radhakrishna U, Winters D, Nath SK, et al. (2009). Localization of a gene for keratoconus to a 5.6-Mb interval on 13q32. Invest. Ophthalmol. Vis. Sci. 50: 1531-1539. http://dx.doi.org/10.1167/iovs.08-2173

Georgiou T, Funnell CL, Cassels-Brown A and O'Conor R (2004). Influence of ethnic origin on the incidence of keratoconus and associated atopic disease in Asians and white patients. Eye (Lond.) 18: 379-383. http://dx.doi. org $/ 10.1038 /$ sj.eye. 6700652

Gomes JA, Tan D, Rapuano CJ, Belin MW, et al.; Group of Panelists for the Global Delphi Panel of Keratoconus and Ectatic Diseases (2015). Global consensus on keratoconus and ectatic diseases. Cornea 34: 359-369. http://dx.doi. org $/ 10.1097 / \mathrm{ICO} .0000000000000408$

Hayashi T, Huang J and Deeb SS (2000). RINX(VSX1), a novel homeobox gene expressed in the inner nuclear layer of the adult retina. Genomics 67: 128-139. http://dx.doi.org/10.1006/geno.2000.6248

Héon E, Greenberg A, Kopp KK, Rootman D, et al. (2002). VSX1: a gene for posterior polymorphous dystrophy and keratoconus. Hum. Mol. Genet. 11: 1029-1036. http://dx.doi.org/10.1093/hmg/11.9.1029

Jeoung JW, Kim MK, Park SS, Kim SY, et al. (2012). VSX1 gene and keratoconus: genetic analysis in Korean patients. Cornea 31: 746-750. http://dx.doi.org/10.1097/ICO.0b013e3181e16dd0

Kymes SM, Walline JJ, Zadnik K, Sterling J, et al.; Collaborative Longitudinal Evaluation of Keratoconus Study Group (2008). Changes in the quality-of-life of people with keratoconus. Am. J. Ophthalmol. 145: 611-617. http://dx.doi. org/10.1016/j.ajo.2007.11.017

Lema I and Durán JA (2005). Inflammatory molecules in the tears of patients with keratoconus. Ophthalmology 112: 654659. http://dx.doi.org/10.1016/j.ophtha.2004.11.050

Li X, Bykhovskaya Y, Haritunians T, Siscovick D, et al. (2012). A genome-wide association study identifies a potential novel gene locus for keratoconus, one of the commonest causes for corneal transplantation in developed countries. Hum. Mol. Genet. 21: 421-429. http://dx.doi.org/10.1093/hmg/ddr460

Liskova P, Ebenezer ND, Hysi PG, Gwilliam R, et al. (2007). Molecular analysis of the VSX1 gene in familial keratoconus. Mol. Vis. 13: 1887-1891.

Lv YP, Yao WJ, Chen J and Bao BL (2015). Newly identified gene muscle segment homeobox C may play a role in intermuscular bone development of Hemibarbus labeo. Genet. Mol. Res. 14: 11324-11334. http://dx.doi. org/10.4238/2015.September.22.26

Matthews FJ, Cook SD, Majid MA, Dick AD, et al. (2007). Changes in the balance of the tissue inhibitor of matrix metalloproteinases (TIMPs)-1 and -3 may promote keratocyte apoptosis in keratoconus. Exp. Eye Res. 84: 11251134. http://dx.doi.org/10.1016/j.exer.2007.02.013

McGhee CN (2009). 2008 Sir Norman McAlister Gregg Lecture: 150 years of practical observations on the conical cornea--what have we learned? Clin. Experiment. Ophthalmol. 37: 160-176. http://dx.doi.org/10.1111/j.14429071.2009.02009.x

Mok JW, Baek SJ and Joo CK (2008). VSX1 gene variants are associated with keratoconus in unrelated Korean patients. J. Hum. Genet. 53: 842-849. http://dx.doi.org/10.1007/s10038-008-0319-6

Moreira LB, Bardal RA and Crisigiovanni LR (2013). Contact lenses fitting after intracorneal ring segments implantation in keratoconus. Arq. Bras. Oftalmol. 76: 215-217. http://dx.doi.org/10.1590/S0004-27492013000400004

Genetics and Molecular Research 15 (4): gmr15049024 
Ohtoshi A, Wang SW, Maeda H, Saszik SM, et al. (2004). Regulation of retinal cone bipolar cell differentiation and photopic vision by the CVC homeobox gene Vsx1. Curr. Biol. 14: 530-536. http://dx.doi.org/10.1016/j.cub.2004.02.027

Paliwal P, Tandon R, Dube D, Kaur P, et al. (2011). Familial segregation of a VSX1 mutation adds a new dimension to its role in the causation of keratoconus. Mol. Vis. 17: 481-485.

Rabinowitz YS (1998). Keratoconus. Surv. Ophthalmol. 42: 297-319. http://dx.doi.org/10.1016/S0039-6257(97)00119-7

Romero-Jiménez M, Santodomingo-Rubido J and Wolffsohn JS (2010). Keratoconus: a review. Cont. Lens Anterior Eye 33: 157-166, quiz 205. http://dx.doi.org/10.1016/j.clae.2010.04.006

Saee-Rad S, Hashemi H, Miraftab M, Noori-Daloii MR, et al. (2011). Mutation analysis of VSX1 and SOD1 in Iranian patients with keratoconus. Mol. Vis. 17: 3128-3136.

Schwarz JM, Cooper DN, Schuelke M and Seelow D (2014). MutationTaster2: mutation prediction for the deep-sequencing age. Nat. Methods 11: 361-362. http://dx.doi.org/10.1038/nmeth.2890

Semina EV, Mintz-Hittner HA and Murray JC (2000). Isolation and characterization of a novel human paired-like homeodomain-containing transcription factor gene, VSX1, expressed in ocular tissues. Genomics 63: 289-293. http:// dx.doi.org/10.1006/geno.1999.6093

Shetty R, Nuijts RM, Nanaiah SG, Anandula VR, et al. (2015). Two novel missense substitutions in the VSX1 gene: clinical and genetic analysis of families with Keratoconus from India. BMC Med. Genet. 16: 33-43. http://dx.doi. org/10.1186/s12881-015-0178-x

Tanwar M, Kumar M, Nayak B, Pathak D, et al. (2010). VSX1 gene analysis in keratoconus. Mol. Vis. 16: 2395-2401.

Vincent AL, Jordan C, Sheck L, Niederer R, et al. (2013). Screening the visual system homeobox 1 gene in keratoconus and posterior polymorphous dystrophy cohorts identifies a novel variant. Mol. Vis. 19: 852-860.

Wang Y, Rabinowitz YS, Rotter JI and Yang H (2000). Genetic epidemiological study of keratoconus: evidence for major gene determination. Am.J. Med. Genet. 93:403-409. http://dx.doi.org/10.1002/1096-8628(20000828)93:5<403::AIDAJMG11>3.0.CO;2-A

Watson T and Chow RL (2011). Absence of Vsx1 expression in the normal and damaged mouse cornea. Mol. Vis. 17: 737-744.

Wheeler J, Hauser MA, Afshari NA, Allingham RR, et al. (2012). The genetics of keratoconus: a review. Reprod. Syst. Sex Disord. (Suppl 6): 001. 